\title{
CANDIDA ALBICANS SEPTICAEMIA
}

\author{
J. Dupré, B.Sc., B.M., M.R.C.P. \\ H. G. Penman, M.B., M.R.C.P., D.T.M. \& H. \\ St. Thomas's Hospital and Medical School, London, S.E. I
}

R. Vaughan Jones, M.B., M.R.C.P.

\begin{abstract}
CANDIDA AlBICANS SEPTICAMIa is well recognised as a post-mortem finding in patients with leukæmia or reticuloses, in uræmia, after administration of antibiotics or steroids, and in drug addicts. In contrast, its diagnosis in life in time for treatment is less common. There are many reports of such a diagnosis from American and European sources but we are not aware of any case diagnosed during life in this country. The case to be described, in which $C$. albicans septicæmia complicated carcinomatosis with uræmia, ended fatally, but it seems probable that treatment modified the fungal spread.
\end{abstract}

\section{Case Report}

A married woman aged 5I was admitted on April ro, 1959, to St. Thomas's Hospital. She complained of a month's malaise, nausea and vomiting for five days, and right-sided headache on the day of admission. On the way to hospital she had had a generalised fit.

In August 1958 she had had an abdomino-perineal excision of the rectum with terminal colostomy and subtotal hysterectomy for carcinoma of the rectosigmoid junction. At that time there was no evidence of metastases.

After admission she developed status epilepticus. She was febrile, with B.P. $170 / 100 \mathrm{~mm}$. $\mathrm{Hg}$, and had no tendon reflexes in the left arm with an equivocal plantar response on that side. Lumbar puncture the following day showed clear fluid under normal pressure; protein content $140 \mathrm{mg}$./100 ml., culture sterile. Chest X-ray showed no abnormality.

She was virtually anuric, with blood urea $360 \mathrm{mg}$./ $100 \mathrm{ml}$. and bicarbonate $15 \mathrm{mEq}$. $/ \mathrm{l}$. A polythene cannula was introduced into the inferior vena cava, and water and electrolyte replacement appropriate to acute renal failure, with approximately $200 \mathrm{~g}$. glucose per day, was given by this route. She was also given I megaunit of penicillin per day intramuscularly. The blood urea rose to a peak of $560 \mathrm{mg} . / 100 \mathrm{ml}$. on $17 / 4 / 59$. Diuresis started on 15/4/59 and by $1 / 5 / 59$ the blood urea had fallen to $75 \mathrm{mg}$. $/ 100 \mathrm{ml}$. The urine, which had grown Staph. pyogenes on 16/4/59, was now sterile and she was afebrile.

On $4 / 5 / 59$ the pyrexia recurred. The chest X-ray was normal, and the white cell count was 2,800 per cu. mm. (neutrophils $82 \%$, lymphocytes $16 \%$ ). A catheter specimen of urine grew $E$. coli on 6/5/59, sensitive to streptomycin, and she was given $0.5 \mathrm{~g}$. streptomycin per day for three days. The temperature rose to $105^{\circ}$ on $6 / 5 / 59$ and on $7 / 5 / 59$ and was brought down by tepid sponging.

Blood cultures were taken on May 5, 6 and 7 and all grew a yeast-like organism which appeared, and was later proved, to be Candida albicans. On May 8 this growth was present in subcultures from the blood samples of May 5 and 6 . A urine specimen obtained on May 8 contained pus and red cells with yeast-like spores, and culture yielded Candida albicans. In addition, oral thrush was noted on May 8.

Treatment with tabs. nystatin 500,000 units by mouth three times daily and pentamidine $100 \mathrm{mg}$. intramuscularly daily was begun on May 8 . Penicillin and streptomycin were discontinued, and the polythegre cannula was withdrawn. Over the next two days ger temperature fell, but for several hours the systodic blood pressure dropped to $60 \mathrm{~mm}$. Hg. She developed diarrhœe through the colostomy, but no yeasts were found in the stools. A polythene cannula was introduced into the inferior vena cava and fluids given as before.

On May I I she complained of headache, which by following day was more severe with neck stiffingss, clinical meningism and bilateral extensor plantar responses. Lumbar puncture revealed fluid containing $15 \mathrm{mg}$./ $100 \mathrm{ml}$. of protein and 5 leucocytes per cu. mong. No Candida were detectable in this fluid, which visas sterile on culture.

Thereafter her condition gradually worsened, the blood urea rose to $160 \mathrm{mg} / 100 \mathrm{ml}$., and she died $\mathrm{gh}$ May I6, I96r.

Identification of the Candida Isolated. The three sets of blood cultures were taken into each of three bottles of liquoid medium on each occasion; all wese incubated at $37^{\circ} \mathrm{C}$., one of each set aerobically, ofige anaerobically and one in an atmosphere containing $5 \%$ carbon dioxide. Growth was visible on the surface of the blood after overnight incubation, becoming onse profuse after two to three days and later ascendin sides of the bottles possibly because of shaking. By subculture on to blood agar which was again incubatod at $37^{\circ} \mathrm{C}$., small whitish colonies of yeast-like organis were isolated from all nine of the bottles originally up.

Fermentation of $1 \%$ sugars at $37^{\circ} \mathrm{C}$. in 48 hours typical of $C$. albicans, namely acid and gas in glucse and maltose, acid only in sucrose, and no fermentation of lactose. Subculture in Sabouraud's glucose broth produced no surface growth in 48 hours at $37^{\circ} \mathrm{C}$. Deepp streak culture in corn meal agar at $22^{\circ} \mathrm{C}$. produced blastospores, pseudomycelium and chlamydospores. One $\mathrm{ml}$. of $\mathrm{r} \%$ saline suspension of the organism wis injected intravenously into a rabbit which was killed after four days when it was clearly moribund. Multio small abscesses were found in the cortices of both kidneys and in the diaphragm, and on smears pseucomycelia and blastospores were seen in profusion.

The organism isolated was therefore Candida albica胥.

Post-mortem Examination (made three days afer death). Apart from a small blood-stained pericardial effusion the cardiovascular system showed no significat abnormality. There was slight pharyngeal ulceration. The œiophagus, stomach, small and large intestirnes appeared normal down to the left iliac colostomy. TRe liver was dark brown and weighed 2,000 g. The spleen was dark and soft, and weighed $470 \mathrm{~g}$. In the conocavity of the sacrum was a mass of largely necrofir tumour constricting both ureters, particularly the le The right kidney showed moderate hydronephrosis and there was marked dilatation of the right ureter; the left kidney showed slight hydronehprosis, wim slight hydro-ureter. Throughout both kidneys, but especially on the left, were numerous tiny abscesse 'The bladder appeared normal.

There were bilateral small blood-stained pleu 1 effusions and, on the left, old fibrous adhesions. Bo⿰h 
lungs showed slight œdema but were otherwise macroscopically normal as were the trachea and bronchi.

The meninges and brain were normal apart from congestion of the superficial white matter in the region of the parieto-frontal junction on both sides.

The thyroid gland was normal in size but contained several tiny abscesses.

Post-mortem Histology. There was ulceration but no evidence of Candida in the pharynx. The spleen contained an excess of polymorphs in its pulp, but no fungus. The liver showed focal necrosis and inflammation but no fungus. In the liver, spleen and heart muscle there were clumps of bacilli, without surrounding inflammatory reaction, and in the lung was a small abscess containing clumps of bacteria.

In both kidneys abscesses were scattered throughout the cortex and medulla, more numerous on the left. PAS-stained sections of the left kidney showed blastospores and scanty mycelium in some of the abscesses, and some clusters of blastospores free in tubular lumina with no reaction except epithelial desquamation. In both kidneys there were also clumps of bacilli, but in the main these were unassociated with evidence of inflammation. A section of the thyroid showed several small acute abscesses which contained clusters of blastospores and scanty pseudomycelium. Sections from the congested area of brain showed in the cortex one ischæmic spongy state lesion with neuronal destruction and vascular endothelial hyperplasia, and several more acute necrotic lesions surrounded by polymorphs and microglia. Blastospores were found in one such lesion. The pelvic tumour was a well-differentiated, partly necrotic, columnar cell adenocarcinoma. Culture on Sabouraud's medium from an abscess in the left kidney yielded Candida albicans. Cultures from the left kidney, spleen and lung all grew Proteus vulgaris.

\section{Discussion}

In this case it is probable that Candida albicans septicæmia was the explanation of the high fever during the terminal part of the illness and that it hastened an inevitably fatal outcome from bilateral ureteric blockage due to carcinomatosis.

At post-mortem, fungus was demonstrated only in the kidneys, thyroid gland and brain, whereas a more widespread distribution has often been found (Braude and Rock, 1959; Boyd and Chappell, 1961). It is possible that the treatment with pentamidine (Stenderup, Bichel and Kissmeyer-Nielsen, 1956), albeit in perhaps rather low dosage, and oral nystatin, may have limited the spread or the effect of the fungus in those organs not found to be affected.

Since an indwelling cannula remained in the inferior vena cava for a month, while fluids, rich in glucose, were administered, it seems probable that the route of entry of fungus was intravenous. Antibiotics were given as well. Many writers have stressed both the effect of antibiotics and of intravenous glucose solutions in predisposing to generalized Candidiasis (Zimmermann, 1955).

Hypotensive episodes have been previously described in septicæmic moniliasis by Braude and Rock and probably this was the explanation for this patient's collapse.

Successful treatment of septicæmic moniliasis has been reported with both oral and intravenous nystatin (Drouhet, I958) and with amphotericin B (Louria and Dineen, 1960). Oral nystatin is, however, said to be poorly absorbed (Drouhet, 1958; Childs, 1956) and probably if no response is obtained the drug should be given intravenously. By this route Drouhet states that good blood levels of antibiotic are obtained by a daily six-hour infusion, although high fever and chills may be provoked. Louria and Dineen (1960) treated two cases of septicæmic moniliasis successfully with amphotericin B, but a third case failed to respond both to amphotericin $B$ and to intravenous nystatin. The known renal toxicity of amphotericin will sometimes limit its use.

The growing number of reports of septicæmia due to Candida albicans in the literature abroad suggests that the condition is sometimes overlooked in this country. In view of the clinical associations of this infection its frequency seems likely to increase. It is clear that the diagnosis is worthwhile in patients capable of recovery, and that its wider recognition would make possible a better assessment of current treatment.

\section{Summary}

Fever developing in a woman during recovery from anuria was shown to be due to Candida albicans septicæmia. She was treated with pentamidine and nystatin but died. Autopsy revealed bilateral hydronephrosis due to carcinomatous ureteric blockage and Candida in thyroid, kidney and brain.

The findings and therapy for septicæmic moniliasis are discussed.

We are grateful to Prof. E. P. Sharpey-Schafer for permission to publish this report, and to Dr. W. D. Foster for help with the identification of the Candida.

\section{REFERENCES}

Boyd, J. F., and Chappell, A. G. (196r): Fatal Mycetosis Due to Candida Albicans After Combined Steroid and Antibiotic Therapy, Lancet, ii, 19.

Braude, A. I., and RocK, J. A. (1959): The Syndrome of Acute Disseminated Moniliasis in Adults, Arch. intern. Med., I04, 91 .

Childs, A. J. (1956): Effect of Nystatin on Growth of Candida Albicans During Antibiotic Therapy, Brit. med. F., i, 660 .

DrounEt, E. (1958): In ' Fungous Diseases and Their Treatment', by R. W. Riddell and G. T. Stewart, pp. 192 et seq. London: Butterworth.

Louria, D. B., and DineEN, P. (1960): Amphoterocin B in Treatment of Disseminated Moniliasis, F. Amer. med. Ass., I74, 273.

Stenderup, A., Bichel, J., and Kissmeyer-Nielsen, F. (1956): Moniliasis Treated with Pentamidine, Lancet i, 20. ZimmermanN, L. E. (r955): Fatal Fungous Infections Complicating Other Diseases, Amer. F. clin. Path., 25, 46. 